\title{
MELTING, MECHANICAL WORKING, AND SOME PHYS. ICAL PROPERTIES OF RHODIUM
}

\author{
By Wm. H. Swanger
}

\section{ABSTRACT}

In continuation of the work on the platinum metals a method for the purification, and the technic for the melting and mechanical working of rhodium have been developed. New determinations of a number of the physical constants of rhodium have been made on the specially purified material.

The melting point of rhodium has been determined as $1,985^{\circ} \mathrm{C} . \pm 10^{\circ}$. The metal can be melted with an oxyhydrogen flame on a block of hard-burned lime or in vacuum by means of the high-frequency induction furnace, using fused thoria crucibles.

The metal as melted is not malleable at room temperature, but can be readily forged at temperatures above $800^{\circ} \mathrm{C}$. It has been hot swaged to wires of $1 \mathrm{~mm}$ diameter. These wires, swaged above $800^{\circ} \mathrm{C}$. are not ductile, and have a coarsegrained, equiaxed structure. By continuing the working of the wire at gradually decreasing temperatures, a fibrous structure is imparted to the wire and it becomes ductile and can be drawn at room temperature.

New determinations of physical properties of rhodium gave the following results: Density, $12.4-\mathrm{g} / \mathrm{cm}^{3}$; length of side of unit cube (face centered) of the rhodium lattice, $a_{\mathrm{o}}=3.77 \mathrm{~A}$; electrical resistivity, 4.93 microhm-centimeters at $20^{\circ}$ C.; thermal emf. against platinum at $1,200^{\circ}$ C., $18.42 \mathrm{mv}$; temperature coefficient of resistance, $0^{\circ}$ to $100^{\circ}$ C., 0.00436 ; average coefficient of thermal expansion $20^{\circ}$ to $50^{\circ} \mathrm{C} . .9 .6 \times 10^{-6}$; hardness (baby Brinell $12.8 \mathrm{~kg}$ load, 1116 -inch ball) 101. The reflecting power is constant across the visible spectrum, but drops off rapidly in the ultra-violet.

\section{CONTENTS}

I. Introduction

II. Preparation of rhodium sponge

III. Melting and working of rhodium

1. Melting in the oxyhydrogen flame

2. Melting in the high-frequency induction furnace...

3. Forging and swaging

4. Drawing of rhodium wire

5. Melting point of rhodium

IV. Other physical properties of rhodium

1. Density

2. X-ray diffraction data.

3. Electrical resistivity

4. Thermal electromotive force against platinum

5. Temperature coefficient of electrical resistance

6. Thermal expansion

7. Reflecting power

8. Hardness

V. Acknowledgment.

\section{INTRODUCTION}

The work done in the past few years at the Bureau of Standards on methods for the purification of the platinum metals has made available very pure material for determining the properties of these metals and of their alloys. The present paper will outline the work 
which has been done on the melting, the mechanical working, and the physical properties of pure rhodium.

Although rhodium has been known since 1804, when it was discovered by Wollaston, its use has been limited almost entirely to the platinum-rhodium alloys for thermocouples, which contain 10 or 13 per cent of rhodium. The lack of its application to other uses has been chiefly due to its scarcity. Crude platinum, its chief source of supply, contains only about 1 per cent of rhodium. According to statistics of the Bureau of Mines, ${ }^{1}$ the stock of rhodium (plus ruthenium and osmium) in the hands of refiners at the end of the year 1927 was 4,369 ounces compared to 68,000 ounces of platinum, and the imports of rhodium into the United States during the year were 1,308 ounces compared to 128,000 ounces of platinum.

Aside from its scarcity, the difficulties in fabrication have probably kept pure rhodium from the list of industrially useful metals. Mention of specimens of mechanically worked rhodium occurs in a few places in the literature, but no description is given as to the methods used, other than that the specimens were prepared only with great difficulty.

\section{PREPARATION OF RHODIUM SPONGE}

The pure rhodium sponge used in the present work for the preparation of rods and wires of rhodium was prepared by the method described by Wichers, Gilchrist, and Swanger. ${ }^{2}$ Briefly this process consisted of heating commercial or crude rhodium, in finely divided form, with sodium chloride in an atmosphere of chlorine gas, to a temperature of about $600^{\circ} \mathrm{C}$. The partially fused mass of sodium rhodium chloride thus obtained was dissolved in water. This solution was then boiled with an excess of sodium nitrite, which converted the rhodium to the soluble sodium rhodium nitrite. A small amount of sodium sulphide was then added to remove lead as sulphide. Some of the platinum and palladium present was also precipitated, but not much of the rhodium. After filtration, a saturated solution of ammonium chloride was added to precipitate ammonium rhodium nitrite $\left(\mathrm{NH}_{4}\right)_{3} \mathrm{Rh}\left(\mathrm{NO}_{2}\right)_{6}$. This salt was easily decomposed by hydrochloric acid, yielding a solution of rhodium chloride. The foregoing process was then repeated as many times as necessary to produce a final product of the desired degree of purity.

As ammonium rhodium nitrite is not a suitable salt for reduction to sponge by ignition, it was converted to ammonium rhodium chloride. This salt was ignited in air, and the somewhat oxidized sponge thus obtained was reduced in hydrogen.

Preparations of rhodium sponge made by this process have shown no impurities by spectrographic examination, except for traces of iridium in some instances. The melts described in the present paper were made from these preparations.

1 Platinum and Allied Metals in 1927, Jewelers Circular, 96, No. 19, p. 55; 1928.

2 E. Wichers, R. Gilchrist, and Wm. H. Swanger, Purification of the Six Platinum Metals, Trans. A. I. M. E., 76, pp. 602-630; 1928. 


\section{MELTING AND WORKING OF RHODIUM}

\section{MELTING IN THE OXYHYDROGEN FLAME}

The first melts of pure rhodium were made with a "hard" (oxygen rich) oxyhydrogen flame, the rhodium being held on a block of hard-burned lime. It was found desirable to press the rhodium sponge into pellets in a steel mold before melting.

As soon as the rhodium melts in the oxyhydrogen flame it begins to spit, small beads of metal are thrown off very rapidly, and when the melt freezes large excrescences form on the surface. This is presumably due to the evolution of gases which have been absorbed from the flame by the molten metal.

By sufficiently reducing the flow of oxygen to the melting torch, this spitting of rhodium can be avoided to a considerable extent and the metal made to freeze with a fairly smooth surface. It is, of course, realized that a flame of this type-that is, a soft flame rich in hydrogen-may reduce lime at the temperature of molten rhodium, and introduce calcium into the melt. However, by proper manipulation of the flame, only the upper portion of the metal is melted at any one time, and the liquid metal can be kept out of contact with the lime while exposed to this soft flame. A button of rhodium melted in this manner can be lifted from the lime block cleanly with no adherence of lime to the metal.

\section{MELTING IN THE HIGH-FREQUENCY INDUCTION FURNACE}

The melting of rhodium sponge in the high-frequency induction furnace with access of air presents somewhat the same difficulties as does melting on lime with the oxyhydrogen flame. The sponge must be compressed to a density sufficient to heat readily from the induced current. If the pellets are heated in air to a bright red and then allowed to cool to room temperature, the sponge will be oxidized to such a degree that it can not be heated readily in the high-frequency furnace. By heating and cooling in hydrogen such oxidized rhodium sponge can be reduced to clean metal which will then heat easily in the induction coil.

Molten rhodium in an open crucible in the induction furnace spits badly, and if the furnace current is shut off suddenly, so that the metal freezes rapidly, large blisters will grow out from the surface. By proper manipulation of the furnace current the metal can be frozen slowly so that a minimum of blistering occurs, and forgeable ingots are obtained.

The first melts in the induction furnace were made in zirconium oxide crucibles similar to those used at the bureau for the melting of pure platinum. ${ }^{3}$ However, it was found that this refractory softened at the temperatures sometimes attained in the molten rhodium. Nevertheless, it broke away cleanly from the frozen metal and with care could be used for the melting of rhodium. One attempt to cast the molten rhodium into a graphite mold was unsuccessful, as most of the metal was ejected from the mold by the rapid evolution of gas on sudden freezing.

${ }^{8}$ L. Jordan, A. A. Peterson, and L. H. Phelps, Refractories for Melting Pure Metals: Iron, Nickel, Platinum, Trans. Am. Electro-chem. Soc., 50, p. 162; 1926. 
A single melt of rhodium was made in an Acheson graphite crucible to confirm the reported solution of carbon by molten rhodium. There was no spitting or sprouting of the metal on freezing. The button was very hard and brittle and could not be forged either hot or cold. The increase in weight of the metal by melting in graphite was 1.8 per cent. The color of the metal was noticeably darker than that of pure rhodium.

Thorium oxide crucibles were found the most satisfactory for melting pure rhodium in the procedure finally adopted; that is, melting in vacuum in the high-frequency induction furnace. For the preparation of these crucibles pure thorium oxide was fused in the electric arc in a stream of oxygen according to the method described by Fairchild and Peters. ${ }^{4}$ The fused thoria was ground in a steel-ball mill, using steel balls, and was then treated with hydrochloric acid to remove iron. The acid-washed fused oxide was mixed with a small amount of thorium chloride solution, and this mixture was pressed or tamped in suitable molds designed to form a crucible with a wall thickness of about $3 \mathrm{~mm}$. The molded crucibles were dried and then fired to $1,700^{\circ}$ to $1,800^{\circ} \mathrm{C}$. in an Arsem furnace. Care had to be taken in this firing to avoid direct contact between thoria and graphite at temperatures much above $1,200^{\circ} \mathrm{C}$. Thoria crucibles prepared in this manner are very.dense and possess considerable strength. They have been used to melt platinum metal alloys at temperatures up to $2,200^{\circ} \mathrm{C}$.

The melting of rhodium in vacuum in the high-frequency furnace will be described in more detail under the discussion of the melting point of rhodium. It is sufficient for the present to state that melts in vacuum were made in thoria crucibles at a pressure of 0.5 to $1.0 \mathrm{~mm}$ of mercury. Rhodium melted under these conditions froze with a smooth surface of a silver-white color. Ingots of the maximum density reported for rhodium have been obtained in this way.

\section{FORGING AND SWAGING}

The vacuum melts of rhodium weighed usually about $50 \mathrm{~g}$ each. They were made in thoria crucibles measuring about $22 \mathrm{~mm}$ in diameter at the top, $12 \mathrm{~mm}$ at the bottom, and $30 \mathrm{~mm}$ deep (all inside dimensions). These melts were allowed to freeze in the crucibles. The ingots were about $20 \mathrm{~mm}$ long. The shrinkage cavity generally extended over so large a portion of the length of these small ingots that satisfactory forgings could not be made from them.

Several vacuum-fused ingots broke up when forging was attempted. The crystals of these ingots were very large-up to 5 or $6 \mathrm{~mm}$ acrossand the fractures appeared to be intercrystalline. On the other hand, a number of ingots prepared in apparently the same way from the same lot of rhodium sponge and having just as large crystals were forgeable. It has not yet been found possible to control the forgeability of the vacuum-fused metal.

Vacuum-melted ingots remelted on lime with the oxyhydrogen flame, however, always proved forgeable and this procedure was followed in preparing rods and wire. The forging or swaging of the remelted rhodium ingots did not present any unusual difficulties.

C. O. Fairchild and M. F. Peters, U. S. Patent No. 1545951; July 14, 1925. 
These ingots could not be forged at room temperature, but became quite malleable above a red heat.

For the production of wire the ingots were hand forged at about $1,100^{\circ} \mathrm{C}$. to bars of a shape and size (diameter of $10 \mathrm{~mm}$ ) suitable for swaging. The bars were heated in an oxygas or oxyhydrogen flame and entered the swaging dies at about $1,000^{\circ} \mathrm{C}$. A rotary swager operating at $400 \mathrm{r}$. p. m. was used for bars from 10 to $1.8 \mathrm{~mm}$ in diameter. A smaller machine, operating at 600 r. p. m., was used for further swaging to $1.0 \mathrm{~mm}$. Although dies were available for this machine to produce wire of $0.8 \mathrm{~mm}$ diameter, it was found that the machine would not pass the wire through fast enough to prevent its cooling below the temperature at which it was malleable. Consequently the hot swaging of rhodium wire of any considerable length was not carried to sizes below $1.0 \mathrm{~mm}$.

A piece of $1 \mathrm{~mm}$ wire about 35 feet long was prepared by hot swaging to be used as a winding for a resistance furnace in a study of certain reactions at temperatures higher than could be obtained in a platinum-wound furnace. This wire was wound on a grooved alundum tube 1.5 inches in diameter with six turns per linear inch. It was heated to a red heat with a gas flame as it was wound on the tube. The furnace has been kept at a temperature of $1,875^{\circ} \mathrm{C}$. for four hours, although it is not intended to be used regularly at temperatures quite this high.

At the present time data are not available on the rate of deterioration of rhodium wire due to volatilization when used at high temperatures. When rhodium is heated to relatively low temperatures in air it becomes covered with an oxide film which disappears when the temperature reaches about $1,200^{\circ} \mathrm{C}$. If it is quenched in water or dilute hydrochloric acid from above this temperature it remains bright with a silvery white luster.

\section{DRAWING OF RHODIUM WIRE}

The rhodium wire produced by swaging at $800^{\circ} \mathrm{C}$. or over was not ductile at room temperature. It could not be straightened out from a sharp bend without fracturing, nor reduced in diameter by colddrawing. The fracture appeared coarsely crystalline. The end of a piece of such wire could be flattened on an anvil to half its thickness by one sharp blow with a hammer, but fractured when the same thing was attempted with several light blows.

It was thought that if a fibrous structure could be imparted to the hot-swaged wire it might become ductile. In view of the results obtained in the hot-drawing of rhodium this probably could be accomplished during swaging by gradually lowering the temperature of the wire as it is passed through the successively smaller dies until finally it might be swaged at a temperature considerably below a red heat or cold-drawn at room temperature. However, there was not enough material available for much experimental work along this line.

Recently, through the courtesy of Dr. S. L. Hoyt, of the General Electric Research Laboratory, a set of tungsten carbide wire drawing dies, covering the range 0.41 to $0.020 \mathrm{inch}$, was made available to the bureau. These dies can be used at a red heat. A piece of wire which had been hot-swaged to a diameter of $1 \mathrm{~mm}$ was successfully drawn 
through this series of dies to approximately $0.5 \mathrm{~mm}(0.020$ inch) in diameter. The dies were kept at about $600^{\circ} \mathrm{C}$. by means of a gas burner. The wire was heated somewhat hotter $\left(600^{\circ}\right.$ to $800^{\circ} \mathrm{C}$.) as it passed through the die for the first three or four steps in reduction, but the temperature of the wire was gradually lowered until, for the last three or four dies, the wire was well below a red heat. The wire was lubricated by dipping it into a suspension of fine graphite in oil before each pass through the die. After this hot drawing operation the wire, now 0.020 inch in diameter, was drawn through a set of jewel dies at room temperature, without any annealing, to 0.0144 inch. The resulting wire was ductile and could be bent sharply and straightened, coiled on an 8-inch rod, and twisted tightly upon itself without breaking, all at room temperature. It is quite probable that drawing at room temperature could be continued to wire of still smaller size. It is thus demonstrated that rhodium which has heretofore generally been reported as unworkable can be made ductile.

The microstructure of a longitudinal section of wire swaged to 0.040 inch diameter at a temperature above $800^{\circ} \mathrm{C}$. is shown in Figure 1. The microstructure of a longitudinal section of a piece of the swaged wire after it was drawn to 0.014 inch diameter, as described in the preceding paragraph, is shown in Figure 2.

The change from the relatively coarse-grained equiaxed structure of the swaged wire to the distinctly fibrous structure of the ductile wire is clearly seen.

\section{MELTING POINT OF RHODIUM}

One of the most useful applications of rhodium wire appeared to be for windings for high-temperature furnaces or heaters. Rhodium has a melting point considerably higher than platinum and like platinum does not readily oxidize or volatilize in air at high temperatures. In this connection it seemed advisable to redetermine the melting point of rhodium. The figures generally given in the literature for the melting point of rhodium, namely, $1,950^{\circ}$ or $1,955^{\circ} \mathrm{C}$., were based on determinations made on metal which was probably not of the highest purity.

With the collaboration of H. T. Wensel, W. F. Roeser, and F. R. Caldwell, of the pyrometry section of the bureau, a number of determinations of the melting point of rhodium were made. An AjaxNorthrup high-frequency induction furnace was used for melting the rhodium. The arrangement is shown in Figure 3 . The metal was melted in a thoria crucible, $A$, within a closed-end fused silica tube, $D$, which was evacuated. For heat insulation, ignited, but not fused, powdered thorium oxide, $C$, was packed about the crucible. An alundum extraction thimble, $B$, was used to hold the heat insulation and crucible inside the silica tube. The top of the silica tube was closed with the clear fused-silica cover plate, $E$, whose absorption correction had been determined. The melting was carried out at pressures below $1 \mathrm{~mm}$ of mercury, with a liquid-air trap between the mechanical vacuum pump and the melting chamber. Temperature measurements were made with a Leeds \& Northrup optical pyrometer sighted into a $2 \mathrm{~mm}$ hole drilled in the ingot to a depth of 10 to $15 \mathrm{~mm}$.

The pyrometer was calibrated in the bureau's pyrometry section, and in addition was checked at the gold point and at the melting point 


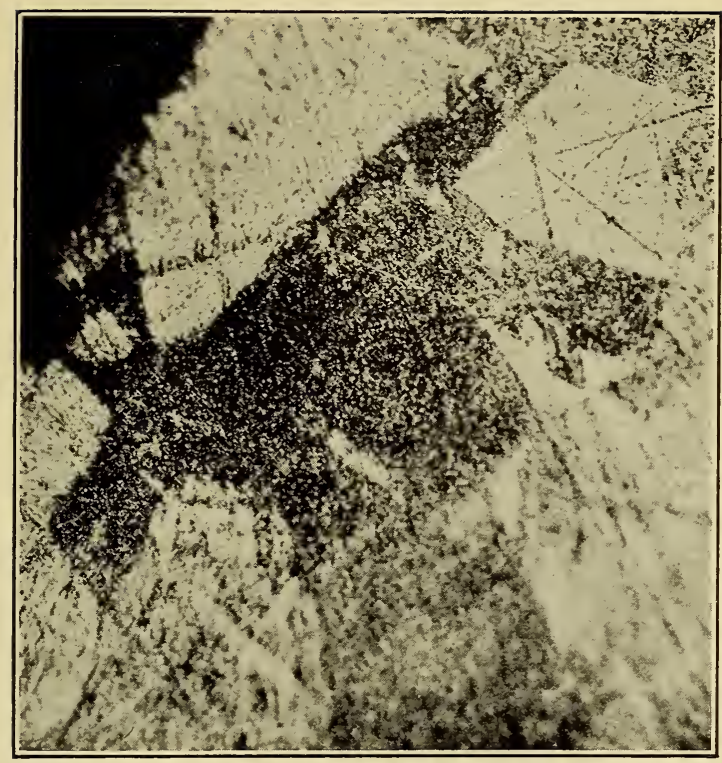

FIGURE 1.-Rh. wire swaged to 0.040 inch diameter at a temperature above $800^{\circ} \mathrm{C} . \times 100$. Etched with fused $\mathrm{KHSO}_{4}$

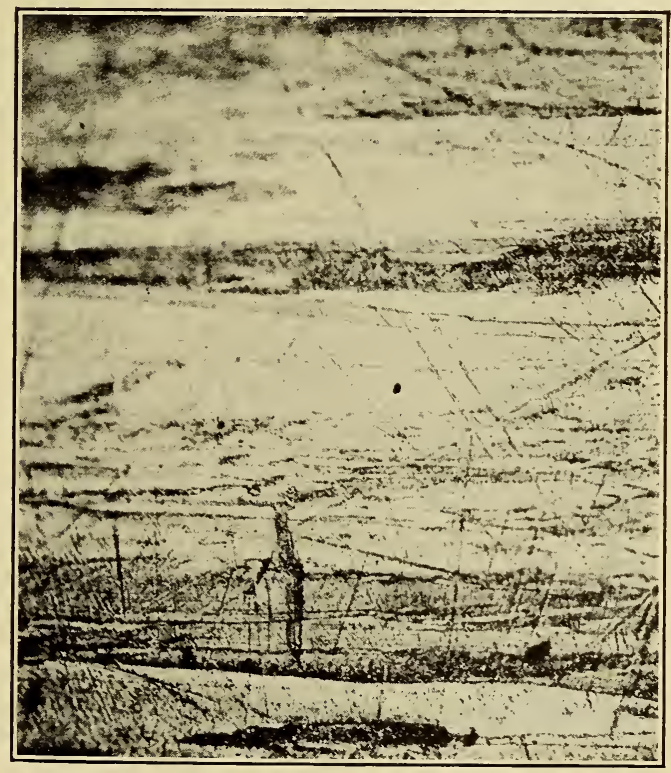

FiguRe 2.-Rh. wire drawn from 0.040 to 0.020 inch diameter at temperatures between $700^{\circ}$ and $400^{\circ} \mathrm{C}$. and from 0.020 to 0.014 inch diameter at room temperature. $\times 100$. Etched with fused $\mathrm{KHSO}_{4}$ 
of platinum using the same high-frequency furnace set-up that was used for determining the melting point of rhodium.

The temperatures corresponding to the melting points were determined both by plotting time-temperature heating curves and by observing the temperature at which the hole in the ingot filled with liquid metal. The flat portion of the heating curve for each melt extended over a period of at least two minutes during which time about 10 readings were taken. In all satisfactory experiments the last temperature reading obtained before the hole in the ingot filled was the same as the temperature corresponding to the flat portion of the heating curve. In some cases the sight hole had not been drilled deep enough into the ingot and the reflection of the cold top portion of the evacuated tube from the bottom of the hole appeared as a dark spot in the center of the image of the hole. This caused an error in that the values obtained for the brightness in the hole were obviously too low. The ratio of the depth of the sight hole to the diameter should be at least 8 to 1 .

Cooling curves could not be taken as satisfactorily as heating curves. In all cases, however, it was

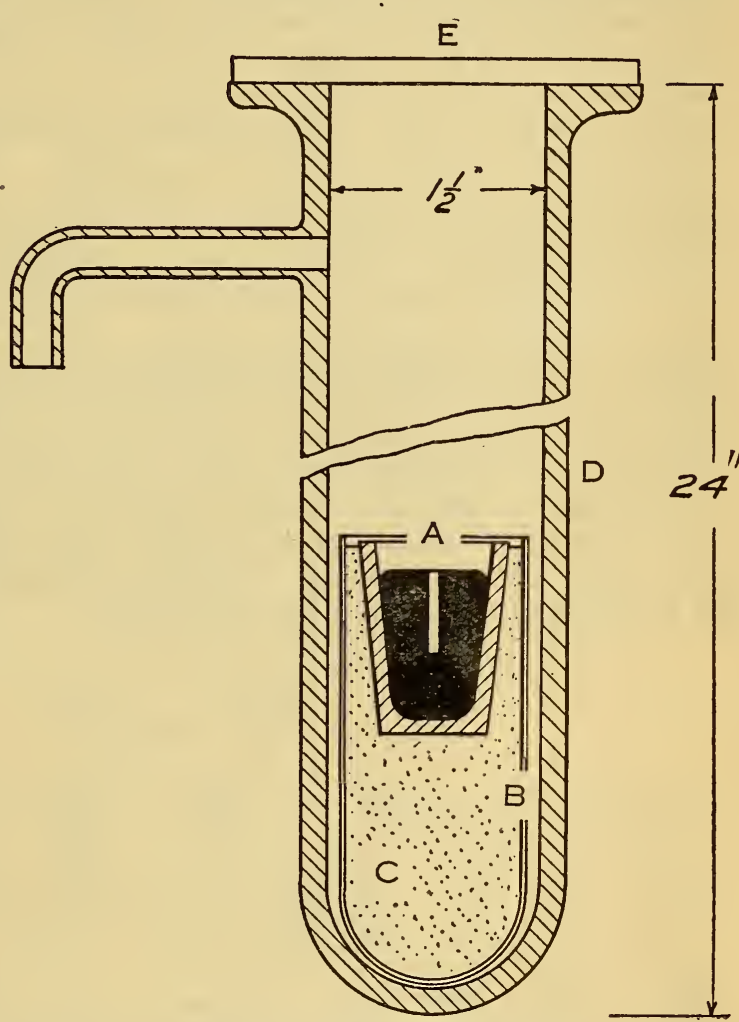

FIgURE 3.-Vacuum furnace assembly for melting rhodium by high-frequency induction possible to obtain two or three constant readings on the liquid surface of the melt while solid metal was spreading over the surface from the sides of the crucible. The correction necessary to convert the apparent temperature obtained by sighting on the freezing liquid surface of rhodium to true temperature was approximated by comparing the brightness in the hole and on the solid surface of several rhodium ingots just below the melting point. The difference in brightness thus obtained was used for correcting the apparent temperature of the liquid surface at the freezing point. This correction is somewhat too large, since the emissivity of liquid rhodium has been found to be slightly higher than that of solid rhodium, and, consequently, the values obtained for the freezing point are presumably somewhat higher than the true value.

$77886^{\circ}-29-14$ 
On two separate ingots, with the best black body conditions in the sight holes, the values for the melting point were $1,986^{\circ}$ and $1,987^{\circ} \mathrm{C}$., respectively. The values for the freezing points from the same two experiments were $2,006^{\circ}$ and $2,002^{\circ} \mathrm{C}$., respectively.

Another series of observations was made ${ }^{5}$ on a third ingot, using a precision optical pyrometer ${ }^{6}$ to make the temperature measurements. An arrangement of furnace, evacuated tube, and crucible similar to that described above was used, except that a "black body" was obtained somewhat differently. Instead of drilling a hole in the ingot and sighting on the bottom of that, a cover (of thorium oxide) was cemented on the crucible. To the bottom of this cover was fixed a thin-walled thorium oxide tube, about $2 \mathrm{~mm}$ inside diameter, and closed at the lower end. The tube projected down through the center of the ingot to the bottom of the crucible. Temperature readings were made by sighting through a hole in the cover into the reentrant tube into which enough loose thorium oxide that had been poured to fill it about one-third of the way from the bottom. This gave a "black body" into which to sight which was about two-thirds of the distance from the top of the ingot to the bottom. It is considered that the temperature measured inside the tube is that of the metal. The metal can thus be melted and frozen a number of times without disturbing the crucible or contents, as long as the sight tube remains intact. On plotting the time-temperature curves for determinations made with this type of crucible there was a flat region on each curve extending over a period of about five minutes. Observations were made on three melts and five freezes. The temperatures corresponding to the flat portions of the curves were as follows:

\begin{tabular}{|c|c|}
\hline Melting & Freezing \\
\hline${ }^{\circ} C$. & ${ }^{\circ} C .98$ \\
1,985 & 1,984 \\
1,984 & 1,985 \\
1,984 & 1,983 \\
\hdashline-986 \\
\hdashline Average.. 1, 984 & 1,983 \\
\hline
\end{tabular}

These values show the precision to which the brightness at the melting and freezing points of rhodium can be determined, but does not necessarily mean that the conversion of these measures of brightness to degrees centigrade was as accurate as the agreement between the separate determinations. Up to the present time accurate checking of the factors entering into this conversion has not been made. The temperatures given above are certainly accurate to within $\pm 10^{\circ}$. The pyrometry section of the bureau, within whose province the accurate determinations of melting points come, is planning to make a more precise determination of the melting point of rhodium in the near future, and the uncertainty of the temperature conversion will then be much less than $10^{\circ} \mathrm{C}$.

From the results of the two methods described, the melting point of rhodium is given tentatively as $1,985^{\circ} \mathrm{C} . \pm 10^{\circ}$.

${ }^{\circ}$ C. O. Fairchild, W. H. Hoover, and M. F. Peters, A New Determination of the Melting Point of Palladium, B. S. Jour. Research, 2 (RP65); May, 1929. 
Most of the tables of physical constants of the elements give the melting point of rhodium as $1,950^{\circ}$ or $1,955^{\circ} \mathrm{C}$. Mendenhall and Ingersoll $^{7}$ determined the melting point of rhodium based on the melting points of gold as $1,065^{\circ} \mathrm{C}$. and of platinum as either $1,745^{\circ}$ or $1,789^{\circ} \mathrm{C}$. Their value was $1,907^{\circ} \mathrm{C}$. $\left(\mathrm{Pt}=1,745^{\circ} \mathrm{C}\right.$.) or $1,968^{\circ} \mathrm{C}$. $\left(\mathrm{Pt}=1,789^{\circ} \mathrm{C}\right.$.). Von Wartenberg ${ }^{8}$ reported his own determinations of the melting point of rhodium as $1,940^{\circ} \mathrm{C}$. based on $C_{2}=1.460 \mathrm{~cm}$ degrees and recalculated a previous determination by Holborn and Henning to $1,946^{\circ} \mathrm{C}$. These two values become approximately $1,970^{\circ}$ and $1,975^{\circ}$ C., respectively, on the International Temperature Scale, which is based on the value $1.432 \mathrm{~cm}$ degrees for $C_{2}{ }^{9}{ }^{9}$

\section{OTHER PHYSICAL PROPERTIES OF RHODIUM}

In the course of the experiments on the melting and working of rhodium, as suitable specimens became available for the determination of physical constants they were submitted to the laboratories of the bureau most directly concerned with the particular measurements required.

New determinations of the following physical constants were made by the members of the bureau staff named below: Density by Miss E. E. Hill, X-ray lattice constant by E. C. Groesbeck, electrical resistivity by $\mathrm{A}$. R. Lindberg, thermal electromotive force and temperature coefficient of resistance by F. R. Caldwell, thermal expansion by W. T. Sweeney, and reflecting power by W. W. Coblentz and R. Stair. Grateful acknowledgment is made for this assistance in obtaining new data on the properties of rhodium. A number of hardness determinations made by the author are also included.

A short description of the above determinations follows:

\section{DENSITY}

Previous determinations of the density of rhodium reported in the literature range from 11.0, the value given by Wollaston in 1804, to $12.6\left(\mathrm{~g} / \mathrm{cm}^{3}\right)$. Holburn, Austin, and Henning ${ }^{10}$ found a value of 12.44 for rhodium foil prepared by Heraeus. The most recent determinations are by Rose. ${ }^{11}$ He found 12.22 for the density of an ingot which was forged from sponge but not melted. The density of another ingot, melted and forged, was 12.47. In reviewing previous determinations Rose calculated that the value 12.6 given by Mylius and Dietz ${ }^{12}$ would become 12.51 when corrected for the impurities, chiefly iridium, which the rhodium contained. $\mathrm{He}$ further states that the density of pure rhodium, melted and forged, might be provisionally taken as 12.5

In the present work the density of three rhodium ingots after melting in vacuum was $12.42,12.41$, and $12.41 \mathrm{~g} / \mathrm{cm}^{3}$, respectively. The three ingots were then melted together on a block of lime with

7 C. E. Mendenhall and L. R. Ingersoll, The Melting Points of Rhodium and Iridium, Phys. Rev., 25, pp. 1-16; 1907.

8 , $\mathrm{H}$. von Wartenberg, Über optische Temperaturmessung blanker Körper, Verhandl. deut. physik. Ges., 12, "pp. 121-127; 1910 .

${ }^{\prime}$ " $\mathrm{C}_{2}$ " is the constant in Wien's radiation law which, together with the value of $1,063^{\circ} \mathrm{C}$. for the melting point of gold, defines the high temperature scale.

${ }_{10}^{10}$ L. Holborn, F. Henning, L. Austin, Die Zerstäubung und Recristallisation Elektrisch Geglühter Platinmetalle, Wiss. ab. Phys. Tech. Reichsanstalt, 4, p. 87; 1903.

11 Sir Thomas Kirke Rose, On the Density of Rhodium, Jr. Inst. Metals, 33, No. 1, pp. 109-110; 1925.

12 F. Mylius and R. Dietz, Reine Platin-Metalle im Handel, Ber., 31, p. 3189, 1899. 
an oxyhydrogen flame. The button was hot forged and then hot swaged to a rod 7 inches long by 0.265 inch in diameter. The density of this rod was $12.40 \mathrm{~g} / \mathrm{cm}^{3}$. The rod was subsequently hot swaged to 0.040 -inch wire. The density of the wire was also $12.40 \mathrm{~g} / \mathrm{cm}^{3}$.

\section{X-RAY DIFFRACTION DATA}

The crystal lattice of rhodium is face centered cubic. Hull ${ }^{13}$ determined the length of the side of the unit cube, $a_{o}$ to be 3.82 Angstroms. Barth and Lunde ${ }^{14}$ have more recently given $a_{o}=3.794 \mathrm{~A}$. If $a_{o}$ is taken as 3.82 the calculated density of rhodium is 12.16 which is quite certainly lower than the true density. The calculated density becomes 12.43 if $a_{o}=3.794$, a value nearer to the observed density.

Two determinations of the length of the side of the unit cube made on the rhodium sponge used in the present work gave:

First determination $-a_{o}=3.773 \pm 0.0025 \mathrm{~A}$

Second determination $-a_{o}=3.774 \pm 0.002 \mathrm{~A}$

The density calculated from these values is 12.6 , which is somewhat higher than the observed density. However, it is generally agreed that the density calculated from the value for the lattice constant is always higher than the density obtained by direct determination.

\section{ELECTRICAL RESISTIVITY}

The resistivity of pure rhodium as determined on wire hot swaged to a diameter of $1 \mathrm{~mm}$ and annealed at a temperature well over $1,200^{\circ} \mathrm{C}$. was 4.93 microhm-centimeters at $20^{\circ} \mathrm{C}$.

The value given in the International Critical Tables is 5.1 at $20^{\circ} \mathrm{C}$. In Carter's ${ }^{15}$ tabulation of the physical properties of rhodium the resistivity at $0^{\circ} \mathrm{C}$. is given as 5.11 .

\section{THERMAL ELECTROMOTIVE FORCE AGAINST PLATINUM}

The thermal electromotive force of rhodium against the bureau's purest platinum (Pt. standard No. 27) was determined for temperatures of the hot junction from $0^{\circ} \mathrm{C}$. to $1,100^{\circ} \mathrm{C}$. with the cold junction at $0^{\circ} \mathrm{C}$. The results are given in Table 1 .

TABLE 1.-Thermal electromotive force of rhodium against platinum

\begin{tabular}{|c|c|c|c|c|c|}
\hline Temperature & Emf. & Temperature & Emf. & Temperature & Emf. \\
\hline $\begin{array}{l}{ }^{\circ} C . \\
0 \\
100 \\
200 \\
300 \\
400\end{array}$ & $\begin{array}{l}m v \\
0.00 \\
.70 \\
1.61 \\
2.68 \\
3.92\end{array}$ & $\begin{array}{c}{ }^{\circ} \mathrm{C} . \\
500 \\
600 \\
700 \\
800\end{array}$ & $\begin{array}{l}m v \\
5.28 \\
6.77 \\
8.40 \\
10.16\end{array}$ & $\begin{array}{c}{ }^{\circ} C . \\
900 \\
1,000 \\
1,100 \\
1,200\end{array}$ & $\begin{array}{c}m v \\
12.04 \\
14.05 \\
16.18 \\
\cdot 18.42\end{array}$ \\
\hline
\end{tabular}

a Extrapolated.

${ }_{13}$ A. W. Hull, X-Ray Crystal Analysis of Thirteen Common Metals, Phys. Rev., 17, pp. 571-588; 1921. 14 T. Barth and G. Lunde, Der Einfluss der Lanthanidenkontraction usw, Zeit Phys. Chem., 11\%, pp. $478-490 ; 1925$.

18 F. E. Carter, The Platinum Metals and Their Alloys, A. I. M. E., Proc. Inst. Metals Div. p. 759; 1928 


\section{TEMPERATURE COEFFICIENT OF ELECTRICAL RESISTANCE}

At the time this determination was made wire less than $1 \mathrm{~mm}$ in diameter was not available. The resistance of this wire was too low to make a measurement of the change of resistance with change of temperature with reasonable accuracy. To provide a suitable specimen, about $1 \mathrm{~m}$ of the wire was clamped between electrical leads and a current passed through the wire to heat it to dull redness. The hot wire was passed back and forth between the rolls of a small hand rolling mill until a ribbon 0.007 inch thick was obtained. This ribbon was fairly ductile. The resistance was measured at $0^{\circ}$ and at $100^{\circ} \mathrm{C}$. The average temperature coefficient of resistance between these temperatures was 0.00436 . Holborn ${ }^{16}$ reported a value of 0.00443 . Additional determinations of this important physical constant will be made.

\section{THERMAL EXPANSION}

The linear coefficient of thermal expansion of rhodium was determined by the interferometric method. The values given in Table 2 are considered accurate to within 1 per cent.

TABLE 2. Thermal expansion of rhodium

\begin{tabular}{|c|c|}
\hline $\begin{array}{c}\text { Temperature } \\
\text { range }\end{array}$ & $\begin{array}{c}\text { Average coeff- } \\
\text { cient of expan- } \\
\text { sion per degree } \\
\text { centigrade }\end{array}$ \\
\hline ㄷ $C$ & $\times 10-0$ \\
20 to 50 & 8.1 \\
20 to 100 & 8.3 \\
20 to 200 & 8.5 \\
20 to 300 & 8.9 \\
20 to 400 & 9.3 \\
20 to 500 & 9.6 \\
\hline
\end{tabular}

The International Critical Tables give the coefficient of thermal expansion as $8.4 \times 10^{-6}$ at $20^{\circ} \mathrm{C}$. Carter, in his tabulation of the physical properties of the platinum metals, gives $8.4 \times 10^{-6}$ at $20^{\circ} \mathrm{C}$. and $8.5 \times 10^{-6}$ at $40^{\circ} \mathrm{C}$.

\section{REFLECTING POWER}

A determination was made of the reflecting power of rhodium in the visible and in the ultra-violet spectrum to wave length $250 \mathrm{~m} \mu$. The surface of the ingot that was used did not have a good polish and diffused considerable radiation. Instead of having a reflecting power of 78 per cent in the visible spectrum as previously determined by Coblentz ${ }^{17}$ it was only about 45 per cent. However, the reflecting power was fairly constant across the visible spectrum, but dropped off rapidly in the ultra-violet until at $250 \mathrm{~m} \mu$ it was about two-thirds of the value in the visible spectrum.

${ }^{10} \mathrm{~L}$. Holborn, Uber die Abhängigkeit des Widerstandes reiner Metalle von der Temperatur, Ann. d. Physik. (4), 59, p. 145; 1919.

17 W. W. Coblentz, The Reflecting Power of Various Metals, B. S. Sci. Paper No, 152. 


\section{HARDNESS}

Hardness determinations were made on several specimens of the melted and forged rhodium. The shape of the specimens as melted made it impracticable to make hardness determinations without forging, although a Brinell number was obtained on the ingot as melted. The hot-forged specimens were annealed at a temperature well over $1,200^{\circ} \mathrm{C}$. The following values were obtained:

TABLE 3.-Hardness of rhodium

\begin{tabular}{|c|c|c|c|}
\hline & $\begin{array}{l}\text { Specimen } \\
\text { A melted, } \\
\text { but not } \\
\text { forged }\end{array}$ & $\begin{array}{c}\text { Specimen } \\
\text { B melted } \\
\text { and } \\
\text { forged }\end{array}$ & $\begin{array}{l}\text { Specimen } \\
\text { C melted } \\
\text { and } \\
\text { forged }\end{array}$ \\
\hline $\begin{array}{l}\text { Baby Brinell } 12.8 \mathrm{~kg}, 1 / 16-i n c h \text { ball } \\
\text { Rockwell “E” } 100 \mathrm{~kg} \text {, 1/8-inch ball } \\
\text { Scleroscope } \\
\text { Vickers hardness tester, } 136^{\circ} \text { diamond pyramid } 10 \mathrm{~kg} \\
\text { Herbert pendulum (time hardness) }\end{array}$ & 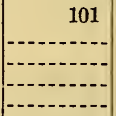 & $\begin{array}{r}101 \\
90 \\
12 \\
121 \\
16.4\end{array}$ & $\begin{array}{r}85 \\
10 \\
125 \\
15\end{array}$ \\
\hline
\end{tabular}

Carter ${ }^{18}$ has given the baby Brinell hardness of cast rhodium as 139.

The hardness values obtained in the present work correspond quite closely with those of hard-rolled copper. Despite this apparent softness, rhodium does not machine readily. Great difficulty was experienced in drilling the sight holes in the specimens used for meltingpoint determinations. An ordinary twist drill made hardly any impression. Flat drills made of carbon-steel drill rod quenched from a bright red heat in ordinary zinc chloride soldering flux seemed to give the best results.

\section{ACKNOWLEDGMENT}

Grateful acknowledgment is made to Louis Jordan, of the metallurgy division, whose aid and advice contributed materially to the accomplishment of the work reported in this paper.

Washington, August 2, 1929. 